\title{
Canada ill-prepared for radiation emergencies
}

$\mathrm{M}$ ost Canadian hospitals are ill-prepared to handle the surge of patients that could result from a large-scale radiation emergency, say Canadian disaster preparedness experts. The ongoing radiation threat in Japan, the result of damage to a nuclear power plant during the country's recent earthquake, has rekindled concerns about the lackadaisical approach to preparing for such an event in Canada, which has 22 nuclear power plants.

"The level of preparedness across the country is poor," says Dr. Carl Jarvis, an emergency physician and director of disaster planning at the Queen Elizabeth II Health Sciences Centre in Halifax, Nova Scotia.

Though many Canadian emergency departments have disaster plans, those plans are often out of date, are infrequently reviewed and are rarely tested using live exercises. Canada also lacks formal guidelines and national standards in preparedness for radiation emergencies.

"Health Canada has no formal guidelines, but has developed with partner organisations a training package to help hospitals and the medical community to prepare for radiation emergencies," Leslie Meerburg, media relations officer for Health Canada, writes in an email. "Health Canada provides this training free of charge to medical communities interested in hosting a training session."

That training package is the METER (Medical Emergency Treatment for Exposures to Radiation) course. From 2007-2009, Jarvis taught the course to first responders and first receivers across Canada. According to Jarvis, the impetus for creating the program was to increase preparedness for a possible terrorist attack during the 2010 Winter Olympics in Vancouver, British Columbia. But national interest in preparing medical professionals for radiation emergencies appears to have waned after the Olympics, says Jarvis,

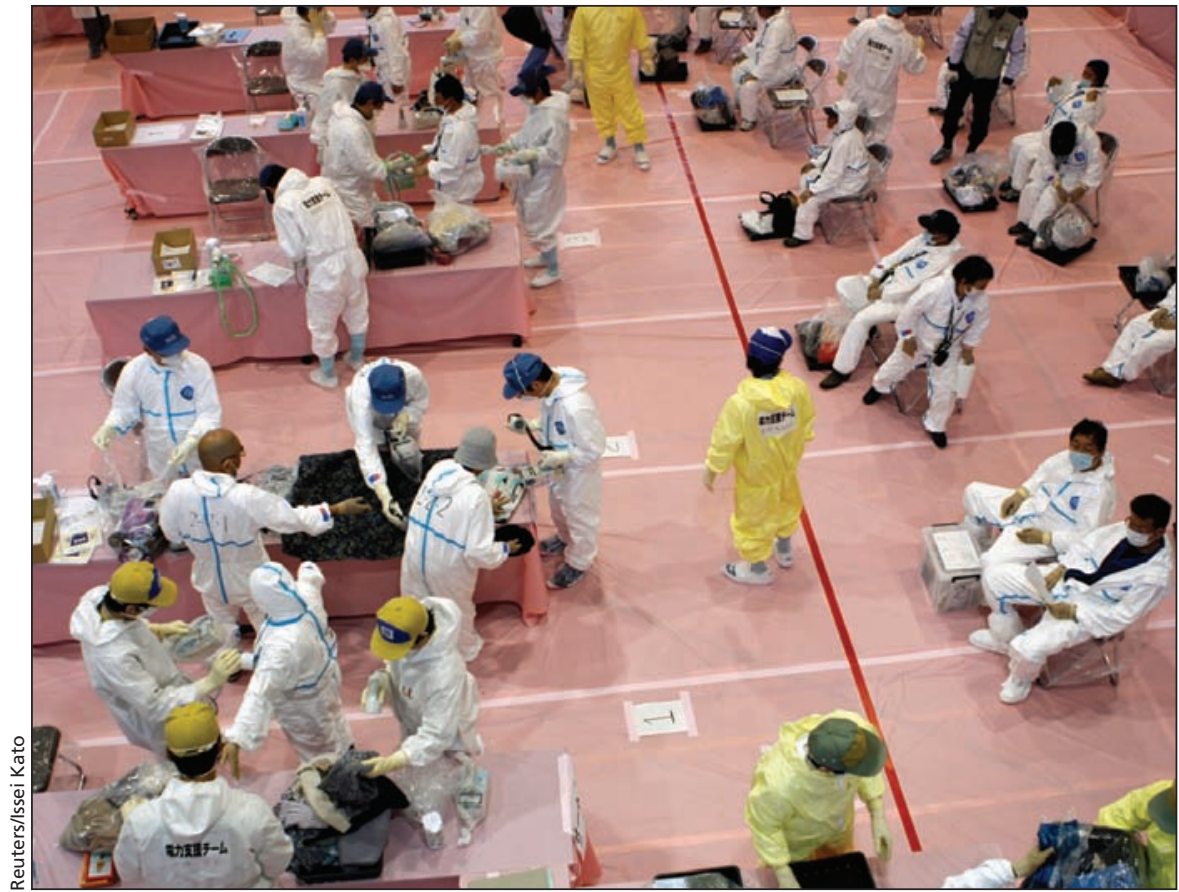

Evacuees from the village of Kawauchi, Japan undergo screening tests for signs of nuclear radiation after returning from brief trips back to their homes inside the restricted zone around Fukushima Daiichi nuclear power plant in the aftermath of the 8.9-magnitude earthquake that rocked the country on March 11th, triggering a sevenmetre tsunami.

who considers this training too important to be tied only to large events.

"We need to get some level of government interested in funding ongoing teaching, particularly in communities near nuclear reactors," he says.

During his training sessions with emergency medical services professionals, Jarvis noticed that there are many misconceptions about radiation and the health risks it poses. For one, few could distinguish between people who were contaminated by radiation (have radioactive material on their bodies and thus require decontamination) and those who were merely exposed to radiation. Some emergency medical services personnel believed it was unsafe to transport a contaminated individual to a hospital. Though this may require that the ambulance later be decontaminated, it poses little risk to paramedics if they take the necessary precautions.
"Provided they are wearing proper PPE, personal protective equipment, there is negligible risk to them," says Jarvis.

These misconceptions will likely persist without ongoing training in Canada. Unfortunately, says Jarvis, emergency department staff and paramedics who wish to be trained in this area may have to travel to the United States, where chemical, biological, radioactive and nuclear (CBRN) disaster preparedness is taken much more seriously.

"There are no Canadian courses where you can send emergency department staff to receive training in CBRN, which is just a travesty," says Jarvis. "How can this void be left year after year?"

One major reason there is little momentum in Canada toward improving disaster preparedness is that responsibility for doing so falls 
between Health Canada and the Public Health Agency of Canada, says Dr. Daniel Kollek, executive director of the Dundas, Ontario-based Centre for Excellence in Emergency Preparedness. The resulting lack of focus in this area translates to a lack of uniformity in hospital preparedness, in quality assessment of existing disaster plans and in training.

"There is no uniformity of training for disaster preparedness. It's not as if it was an issue of having millions of dollars of new equipment. It's just could be decontaminated in the event of a radiation disaster.

The report states that the "key finding" of the study was that Canadian emergency departments "and by inference Canadian hospitals - are unprepared for a CBRN event, this despite their chiefs identifying the ED as being at risk."

A later survey of emergency medical services providers indicated a similar lack of preparedness (CJEM 2009;11:337-42). One in three participants had received no training, theoreti-

\section{"How can this void be left year after year?" - Dr. Carl Jarvis, director of disaster planning at the Queen Elizabeth II Health Sciences Centre in Halifax, Nova Scotia.}

teaching hospitals how to have a plan," says Kollek. "I would like to see a common set of training tools deployed across the country."

In a 2003 survey of emergency department chiefs, Kollek found that many hospitals rarely test or update their disaster plans (CJEM 2003;5:1826). Half of respondents had not reviewed their disaster plans in the previous year. Tests of disaster plans, when they did occur, were usually conducted only on paper, with just $6.7 \%$ running a live exercise in the year prior. Furthermore, only $30 \%$ of emergency departments had areas where patients cal or practical, on how to work in a contaminated area. Less than a third of the 1028 respondents had been trained to provide medical care while wearing personal protective equipment and only $31 \%$ had received training on how to detect radiation.

The paper concludes, on the basis of the survey, that many Canadian emergency medical services providers "have not been trained to identify and work in contaminated environments. When untrained providers are called to respond to a contaminated scene, their lack of knowledge, training and practice threatens the safety" of the providers themselves, as well as that of patients, hospital staff and the health care system.

Though US hospitals are, in general, better prepared than those in Canada to handle a radiation disaster, there are still states in which training is lacking. "It's very spotty in the US. Some states are well-trained and some aren't trained at all," says Dr. Albert Wiley, director of the Radiation Emergency Assistance Center/Training Site (REAC/TS), funded by the US Department of Energy and located in Oak Ridge, Tennessee. "To reach a large number of people in emergency departments would be helpful, but it's hard for them to get time off from their jobs. Webbased training could help, and we are making some attempts at that now."

It would also be helpful if preparedness for radiation emergencies was added to medical school curricula, says Steve Sugarman, health physics project manager for REAC/TS. Then perhaps more medical professionals would realize that, despite the hysteria that often surrounds radiation emergencies, these events are not that difficult to manage and pose little threat to care providers.

"The key message to give to care providers is that this is manageable," says Sugarman. "With a healthy dose of common sense, they can do this with minimal risk to themselves." - Roger Collier, CMAJ

CMAJ 2011. DOI:10.1503/cmaj.109-3890

\section{Demystifying radiation disaster preparedness}

A hospital can prepare for a radiation disaster with relative ease. It doesn't take an immense effort or scads of cash for fancy machines, just common sense and a good plan.

Yet, according to disaster preparedness experts, few Canadian hospitals have made this modest effort (www.cmaj .ca/cgi/doi/10.1503/cmaj.109-3890).

"There is nothing mysterious about radiation illness," says Dr. Albert
Wiley, director of the Radiation Emergency Assistance Center/Training Site (REAC/TS), funded by the US Department of Energy and located in Oak Ridge, Tennessee.

"You diagnose and treat the organ system. The medicines we use are the same medicines we always use, and we use the same diagnostic tools. Yes, there may be a few exotic tests and drugs, but mostly they're what we normally use. The biggest confounder with emergency department staff is that they don't know how to keep their priorities in the presence of radiation."

Many emergency department staff feel unprepared to handle anything involving radiation, says Wiley. But it only takes a few days to ease the worries of people who receive training from REAC/TS (which include many Canadian doctors and nurses because of a lack of ongoing training in Canada). 